\title{
POTRET MASYARAKAT MULTIKULTURAL DI INDONESIA KONSEP DAN IMPLEMENTASI PENDIDIKAN MULTIKULTURAL DI SEKOLAH DASAR (SD) NEGERI DURENSEWU I
}

\author{
${ }^{1}$ Salis Husniatin, ${ }^{2}$ Asrul Anan \\ ${ }^{1}$ salis.husniatin@gmail.com, 2aroelanan@yudharta.ac.id \\ ${ }^{2}$ Universitas Yudharta Pasuruan
}

\begin{abstract}
Research on the concept and implementation of multicultural education for elementary school level students needs to be described and carried out in-depth analysis. Limited learning resources is still related to the implementation of multicultural education for elementary school students. The success or failure in the implementation of Multicultural Education for students in Primary Schools. Thus, this research is focused as follows: 1) What is the concept of multicultural education in SD Negeri Durensewu I Pandaan? 2) How is the implementation of multicultural education in SD Negeri Durensewu I Pandaan ?. 3. Why is success or failure in the implementation of Multicultural Education in Pandaan Durensewu I Primary School?. The results of this study, it was concluded that the concept and implementation of multicultural education in schools was carried out using several approaches, namely the contribution approach, the social action approach and the habituation approach, these were carried out by means of various kinds of activities that existed at school and carried out during teaching and learning activities. In the thematic curriculum applied by schools, there are several subject matter in SD Negeri Durensewu I one of those is elements of multicultural education.
\end{abstract}

Keywords: multicultural, approach, education, learning.

Abstrak: Penelitian tentang konsep dan implementasi pendidikan multikultural untuk siswa tingkat Sekolah Dasar perlu dideskripsikan dan dilakukan analisis lebih mendalam. Masih terbatasnya sumber belajar terkait dengan implementasi 
pendidikan multikultural untuk siswa tingkat Sekolah Dasar. Berhasil atau gagal dalam implementasi Pendidikan Multikultural untuk siswa di Sekolah Dasar. Selanjutnya fokus dari penelitian ini adalah 1) Bagaimana konsep pendidikan multikultural di SD Negeri Durensewu I Pandaan? 2) Bagaimana Implementasi pendidikan multikultural di SD Negeri Durensewu I Pandaan?. 3. Mengapa berhasil atau gagal dalam implementasi Pendidikan Multikultural di Sekolah Dasar Negeri Durensewu I Pandaan? Hasil penelitian ini bahwa konsep dan implementasi pendidikan multikultural disekolah dilaksanakan dengan mengunakan beberapa pendekatan yaitu pendekatan kontribusi, pendekatan aksi sosial dan pendekatan pembiasaan, hal ini dilaksanakan dengan cara berbagai macam kegiatan yang ada di sekolah serta dilaksanakan pada saat kegiatan belajar mengajar. Dalam kurikulum tematik yang diterapkan sekolah ada beberapa materi pelajaran yang ada di SD Negeri Durensewu I terdapat unsur pendidikan multikultural.

Kata kunci : multikultural, pendekatan, pendidikan, pembelajaran.

\section{PENDAHULUAN}

Sekolah merupakan lembaga pendidikan yang didalamnya terdapat kegiatan belajar mengajar antara guru dan siswa. Di sekolah siswa tidak hanya mendapat ilmu pengetahuan saja tetapi juga berlatih berinteraksi dengan orang lain seperti dengan guru serta dengan teman sebaya mereka sesama siswa. Dalam proses berinteraksi di lingkungan sekolah siswa perlu memperhatikan norma-norma yang berlaku, sebab penggunaan norma akan mempengaruhi baik atau buruknya interaksi yang terjalin antar siswa dengan siswa maupun siswa dengan guru.

Sekolah Dasar adalah jenjang paling dasar dalam lembaga pendidikan formal yang ada di Indonesia yang ditempuh dalam 6 tahun. Tujuan pendidikan Sekolah Dasar yakni memberikan bekal kemampuan berupa pengetahuan, sikap, keterampilan yang bermanfaat bagi dirinya untuk mempersiapkan kejenjang pendidikan selanjutnya. ${ }^{1}$

\footnotetext{
${ }^{1}$ Suharjo, Mengenal Pendidikan Sekolah Dasar Teori dan Praktek, (Jakarta: Departemen Pendidikan Nasional Direktorat Jendral Pendidikan Tinggi Direktorat Ketenagaan, 2006), 1.
} 
Negeri Durensewu 1

Peserta didik pada jenjang Sekolah Dasar harus dibekali konsep wawasan pengetahuan secara jelas, supaya tidak ada pengaburan pengetahuan di jenjang selanjutnya. Dalam proses pendidikan Sekolah Dasar memiliki peran membentuk generasi penerus bangsa yang tidak hanya berkualitas dari sisi kognitif saja, namun juga harus dibentuk sikap dan perilaku yang sesuai dengan cita-cita bangsa. Ketidakseimbangan perkembangan aspek pengetahuan, sikap dan keterampilan mengakibatkan generasi muda kelak tidak dapat menjaga keutuhan NKRI. Perlu dukungan komponen pendidikan sesuai fungsi dan tujuannya masing-masing.

Perbedaan agama dan status ekonomi dikalangan peserta didik menyebabkan terjadinya konflik sehingga ketika konflik agak serius menyebabkan peserta didik menangis, guru harus menenangkan dan turun tangan ikut mengatasi, pernah juga terjadi konflik tentang masalah prestasi siswa, karna yang juara olimpiade adalah siswa yang yang beragama Katholik maka menimbulkan kecemburuan sosial bagi siswa yang beragama Islam. $^{2}$

Salah satu fakta yang terjadi di Sekolah Dasar Negeri Durensewu 1 Pandaan saat rapat wali murid siswa yang Beragama Kristen dan Katholik khawatir saat pelajaran pendidikan agama, dikarenakan nanti anaknya terpengaruh kedalam agama Islam. ${ }^{3}$

Oleh karena itu untuk menghindari masalah atau konflik yang ditimbulkan karena banyaknya berbagai macam perbedaan tersebut maka di Sekolah Dasar Negeri Durensewu I Pandaan perlu adanya pendidikan multikultural

\footnotetext{
${ }^{2}$ Bapak Chanafi, S.Pd, Interview, Kantor Kepala Sekolah, (Senin 03 Juni 2019).

${ }^{3}$ Bapak Mustofa , S.PdI, Interview, Ruang Kepala Sekolah, (senin 03 Juni 2019).
} 


\section{PEMBAHASAN \\ Pengertian Implementasi}

Terdapat berbagai pendapat para ahli dan akademisi yang mengemukakan tentang pengertian dari implementasi. Hal ini perlu dijelaskn agar pemahaman tentang implementasi dapat disinkronisasikan dari konsep penelitian terhadap suatu kebijakan atau peraturan perundangan-undangan yang menjadi fokus utama dalam penelitian ini. Karena implementasi merupakan kegiatan yang penting dari keseluruhan proses perencanaan kebijakan. Adapun pengertian implementasi tersebut dapat dilihat dalam beberapa pendapat di bawah ini:

Horn, berpendapat "mengartikan implementasi sebagai tindakantindakan yang dilakukan oleh baik individu-individu/pejabat-pejabatatau kelompok-kelompok pemerintah atau swasta yang diarahkan pada pencapaian tujuan-tujuan yang telah digariskan dalam kebijakan". ${ }^{4}$

\section{Pengertian Pendidikan Multikultural}

Pendidikan dan Multikultural memiliki keterkaitan sebagai subjek dan objek atau yang diterangkan dan menerangkan, juga esensi dan konsekuensi. Pendidikan adalah usaha sadar dan terencana untuk menwujudkan Susana belajar agar peserta didik secara aktif mengembangkan potensi dirinya untuk memiliki kekuatan dan mengembangkan potensi dirinya agar memiliki kekuatan spiritual keagamaan, pengendalian diri, kepribadian, kecerdasan, akhlaq mulia, serta keterampilan yang diperlukan dirinya, masyarakat, bangsa dan Negara. Secara terminologi merupakan proses pengembangan seluruh potensi manusia yang menghargai pluralitas dan heterogenitas sebagai konsekuensi keragaman budaya, etnis, suku dan aliran (agama). ${ }^{5}$ Sehingga, multikulturalisme tidak hanya mengakui adanya

\footnotetext{
${ }^{4}$ Tahir, Arifin. Kebijakan Publik \& Transparansi Penyelenggaraan Pemerintah Daerah.Cetakan Kesatu, (Bandung: Alfabeta CV, 2014), 55.

${ }^{5}$ Maslikhah, Kebijakan Publik dan ..., 48.
} 
16 :.: Konsep dan Implementasi Pendidikan Multikultural di Sekolah Dasar (SD)

Negeri Durensewu 1

keragaman budaya, melainkan juga mengkehendaki adanya penghormatan dari masing-masing budaya yang berbeda.

Pendidikan multikultural ini menghendaki terciptanya pribadipribadi yang sadar akan adanya kemajemukan budaya yang didalamnya banyak terdapat perbedaan-perbedaan, dan tidak berhenti pada sadar saja melainkan juga dapat menghormati keanekaragaman yang ada dalam rangka mewujudkan kerukunan dan kedamaian.

\section{Implementasi Pendidikan Multikultural}

Pelaksanaan pendidikan multikultural, menurut Banks yang dikutip Agus Iswanto, terdapat lima dimensi yang harus ada yaitu, pertama, adanya integrasi pendidikan dalam kurikulum (content integration) yang di dalamnya melibatkan keragaman dalam satu kultur pendidikan yang tujuan utamanya adalah menghapus prasangka. Kedua, konstruksi ilmu pengetahuan (knowledge construction) yang diwujudkan dengan mengetahui dan memahami secara komprehensif keragaman yang ada. Ketiga, pengurangan prasangka (prejudice reduction) yang lahir dari interaksi antar keragaman dalam kultur pendidikan. Keempat, pedagogik kesetaraan manusia (equity pedagogy) yang memberi ruang dan kesempatan yang sama kepada setiap elemen yang beragam. Kelima, pemberdayaan kebudayaan sekolah (empowering school culture). ${ }^{6}$

\begin{tabular}{|l|l|}
\hline JENIS PENDEKATAN & PENJELASAN \\
\hline $\begin{array}{l}\text { Pendekatan kontribusi (the } \\
\text { contributions approach). }\end{array}$ & $\begin{array}{l}\text { Level ini yang paling sering } \\
\text { dilakukan dan paling luas dipakai } \\
\text { dalam fase pertama dari gerakan } \\
\text { kebangkitan etnis. dengan } \\
\text { memasukkan pahlawan/pahlawan } \\
\text { dari suku bangsa/etnis dan benda- } \\
\text { benda budaya ke dalam pelajaran }\end{array}$ \\
\hline
\end{tabular}

\footnotetext{
${ }^{6}$ Agus Iswanto, "Integrasi PAI dan PKn: mengupayakan Pai Yang Berwawasan Multikultural”, dalam Pendidikan Agama Islam Dalam Perspektif Multikulturalisme, hlm. 10.
} 


\begin{tabular}{|l|l|}
\hline \multicolumn{2}{|l|}{ yang sesuai. } \\
\hline Pendekatan aditif (aditif approach). & $\begin{array}{l}\text { Pada tahap ini dilakukan penambahan } \\
\text { materi, konsep, tema, perspektif } \\
\text { terhadap kurikulum tanpa mengubah } \\
\text { struktur, tujuan dan karakteristik } \\
\text { dasarnya. }\end{array}$ \\
\hline $\begin{array}{l}\text { Pendekatan transformasi (the } \\
\text { transformation approach). }\end{array}$ & $\begin{array}{l}\text { Pendekatan transformasi berbeda secara } \\
\text { mendasar dengan pendekatan kontribusi } \\
\text { dan aditif. Pendekatan transformasi } \\
\text { mengubah asumsi dasar kurikulum dan } \\
\text { menumbuhkan kompetensi dasar siswa } \\
\text { dalam melihat konsep, isu, tema, dan } \\
\text { problem dari beberapa perspektif dan } \\
\text { sudut pandang etnis }\end{array}$ \\
\hline $\begin{array}{l}\text { Pendekatan aksi sosial (the sosial action } \\
\text { approach) }\end{array}$ & $\begin{array}{l}\text { mencakup semua elemen dari } \\
\text { pendekatan transformasi, namun } \\
\text { menambah komponen yang } \\
\text { mempersyaratkan siswa membuat aksi } \\
\text { yang berkaitan dengan konsep, isu, atau } \\
\text { masalah yang dipelajari dalam unit. dan } \\
\text { perubahan sosial. }\end{array}$ \\
\hline
\end{tabular}

\section{Keadaan dan letak geografis sekolah}

Sekolah Dasar (SD) Negeri Durensewu I Pandaan terletak di Dusun Bakalan Desa Durensewu Kecamatan Pandaan kabupaten Pasuruan Provinsi Jawa timur. Sekolah Dasar (SD) Negeri Durensewu I Pandaan terletak sekitar

2 Km dari kecamatan Pandaan. ${ }^{7}$ Sekolah Dasar Negeri Durensewu I Kecamatan Pandaan Kabupaten Pasuruan mempunyai visi sebagai berikut “Cerdas, Terampil, Bertaqwa, Berbudaya Dan Ber-Akhlaqul Karimah".

Adapun Misi Sekolah Dasar Negeri Durensewu I Kecamatan Pandaan Kabupaten Pasuruan sebagai berikut :

a. Meningkatkan kompetensi dan profesi tenaga pendidik

b. Meningkatkan mutu pendidikan dan mutu kelulusan

\footnotetext{
${ }^{7}$ Data Dokumentasi SEKOLAH DASARNegeri Durensewu I, SK Gubernur, dikutip tanggal 02 Juli 2019.
} 
18 :.: Konsep dan Implementasi Pendidikan Multikultural di Sekolah Dasar (SD)

Negeri Durensewu 1

c. Menanamkan anak yang Ber-Akhlaqul Karimah

d. Menjalin kerjasama dengan masyarakat

e. Membiasakan 5 S (Salam, Senyum, Sapa, Sopan, Santun) dan 7 K (Keimanan, Keamanan, Ketertiban, Keindahan, Kerindangan, dan Kekeluargaan). ${ }^{8}$

\section{Keadaan Guru, Karyawan dan Siswa}

Jumlah guru dan karyawan yang ada di Sekolah Dasar Negeri I Durensewu Pandaan secara keseluruhan berjumlah 15 Orang beserta kepala sekolah yang terdiri dari 5 guru laki-laki, 8 guru perempuan , 1 orang Karyawan dan 1 Orang Penjaga. ${ }^{9}$ Jumlah seluruh guru adalah 15 orang dengan rincian 5 orang guru tetap (PNS) dan 10 orang guru tidak tetap (Non PNS/sukuan). Dari segi profesionalismenya pun cukup mumpuni karena kebanyakan lulusan sarjana (S1), sebagian kecil terdapat lulusan S2. Yang menjadi Guru kelas berjumlah 10 orang sedangkan yang lain ada yang menjadi Guru Mapel, yaitu 1 orang Guru Mapel Pendidikan Agama Islam dan yang 1 lagi Guru Mapel Penjaskes. Jumlah siswa siswi di SD Negeri Durensewu I Tiga Ratus Dua Puluh Empat (324), yang terdiri dari Seratus Delapan Puluh (180) Siswa Laki-laki dan Seratus empat Belas (114) Siswi Perempuan. Agama yang dianut oleh siswa siwi SD Negeri Durensewu I Beragam terdiri dari Tiga Ratus Empat Belas Siswa-siswi beragama Islam dan sebelas (11) siswa siswi beragama Kristen Khatolik.

\section{Konsep Sekolah dalam pendidikan multikultural}

Konsep Sekolah Dasar Negeri Durensewu I dalam melaksanakan pendidikan multikultural diantaranya yaitu: (1) Konsep dan implementasi pendidikan multikultural pada kegiatan belajar mengajar, (2) Konsep dan

\footnotetext{
${ }^{8}$ Dokumen Sekolah Dasar Negeri Durensewu I, Kurikulum..., hlm. 12, dikutip 02 Juli 2019

${ }^{9}$ Bapak Chanafi, S.Pd, Interview, Ruang Kepala Sekolah, 02 Juli 2019.
} 
Salis Husniatin, Asrul Anan $: \because 19$

implementasi pendidikan multikultural pada materi pembelajaran, (3) Konsep dan implementasi pendidikan multikultural pada kegiatan sekolah

Hasil wawancara dengan kepala sekolah Sekolah Dasar Negeri Durensewu I Pandaan mengatakan bahwa di Sekolah Dasar Negeri Durensewu I Pandaan belum ada tentang Pendidikan multikultural akan tetapi untuk toleransi siswa yang berbeda agama sangat baik meskipun kadang ada sedikit perbedaan antar siswa. ${ }^{10}$

Sedangkan menurut guru mata pelajaran Pendidikan Agama dan Budi Pekerti yaitu Moh Mustofa, S.PdI, meskipun pendidikan multikultural belum dilaksanakan Sekolah Dasar Negeri Durensewu I menurut beliau sebenarnya pendidikan multikultural di Sekolah Dasar Negeri Durensewu I sudah diterapkan, secara tidak langsung yaitu melalui beberapa kegiatan dan cara pelajaran yang telah diterapkan kepada peserta didik. ${ }^{11}$

\begin{tabular}{|l|l|}
\hline Konsep PM di SDN Durensewu I & $\begin{array}{l}\text { Implementasi pendidikan } \\
\text { multikultural }\end{array}$ \\
\hline $\begin{array}{l}\text { Pendidikan multikultular pada } \\
\text { kegiatan belajar mengajar }\end{array}$ & $\begin{array}{l}\text { Tahapan Perencanaan pendidikan } \\
\text { multikultural } \\
\text { Tahapan pelaksanaan pendidikan } \\
\text { multikultural }\end{array}$ \\
\hline $\begin{array}{l}\text { Pendidikan multikultural pada materi } \\
\text { pelajaran }\end{array}$ & $\begin{array}{l}\text { Implementasi pada pelajaran pendidikan } \\
\text { agama } \\
\text { Implementasi pada pelajaran } \\
\text { kewarganegaraan }\end{array}$ \\
\hline $\begin{array}{l}\text { Pendidikan multikultural pada } \\
\text { kegiatan Sekolah }\end{array}$ & $\begin{array}{l}\text { Implementasi pada kegiatan } \\
\text { kemanusiaan } \\
\text { Implementasi pada kegiatan keagamaan }\end{array}$ \\
\hline
\end{tabular}

Tabel Konsep pendidikan multikultural di Sekolah Dasar Negeri Durensewu I

\footnotetext{
${ }^{10}$ Bapak Chanafi, S.Pd, Interview, Ruang kepala sekolah, tanggal 08 Juni 2019.

${ }^{11}$ Bapak Moh. Mustofa, S.PdI, Interview, Ruang Guru, tanggal 10 Juni 2019.
} 
20 :.: Konsep dan Implementasi Pendidikan Multikultural di Sekolah Dasar (SD)

Negeri Durensewu 1

\section{Implementasi pendidikan mutikultural di Sekolah Dasar Negeri Durensewu I Pandaan}

Implementasi pendidikan multikultural di Sekolah Dasar Negeri Durensewu I Pandaan dalam pelaksanaannya dilakukan dengan mencakupi tiga komponen implementasi yaitu implementasi pendidikan multikultural pada kegiatan belajar mengajar, implementasi pada materi pelajaran, dan implementasi pada kegiatan sekolah.

Implementasi Pendidikan Multikultural pada kegiatan belajar mengajar

Implementasi pendidikan multikultural pada kegiatan belajar mengajar, untuk mencapai nilai-nilai pendidikan multikultural yang mencakup tiga komponen kebutuhan yaitu kebutuhan peserta didik, kebutuhan masyarakat dan kebutuhan materi pejaran yang akan disampaikan.

Dalam mencakupi komponen tersebut pihak sekolah SDN Durensewu I melakukan tahapan tahapan dakam menyusunnya yaitu:

\section{Tahap Perencanaan}

Dalam tahap perencanaan pihak sekolah kegiatan yang dilakukan setiap awal tahun yaitu melakukan perencanaan tahunan yang disusun untuk menunjang program kegiatan belajar mengajar, tahap perancanaan ini melibatkan beberapa pihak diantaranya adalah komite sekolah, kepala sekolah, dewan guru dan karyawan sekolah.

Dalam kegiatan penyusunan program sekolah dan program kurikulum diharapkan kepada pihak-pihak yang terlibat memasukkan tentang implementasi pendidikan multikultural sesuai dengan materi dan kebutuhan saat proses implementasi. Agar tercapai dalam implementasi pendidikan multikultural maka pihak Sekolah Dasar Negeri Durensewu I Pandaan dalam menyusun kurikulum mengacu pada visi, misi, dan tujuan sekolah Sekolah Dasar Negeri Durensewu I Pandaan.

\section{Tahap Pelaksanaan}


Salis Husniatin, Asrul Anan :.: 21

Tahap pelaksanaan dilakukan pada saat kegiat belajar mengajar di kelas dan dilaksanakan pada kegiatan sekolah.

\section{Implementasi Pendidikan Multikultural pada materi pelajaran}

Implementasi pendidikan multikultural di Sekolah Dasar Negeri Durensewu I Pandaan dalam pelaksanaannya dilakukan dengan mencakupi dua komponen implementasi yaitu implementasi pada materi pelajaran, implementasi pada proses pelajaran. Proses implementasi dapat dilihat sebagai berikut: ${ }^{12}$

Implementasi pendidikan multikultural pada materi pelajaran

Proses implementasi pendidikan multikultural pada materi pelajaran dilaksanakan sesuai dengan kurikulum yang telah disusun, dalam kurikulum yang disusun dan digunakan di Sekolah Dasar Negeri Durensewu I Pandaan struktur materi pelajaran yang terdapat implementasi pendidikan multikultural diantaranya adalah (a) Materi pelajaran pendidikan agama (b) Materi pelajaran Pendidikan Kewarganegaraan

Dalam kelompok materi pelajaran tersebut direalisasikan pada kegiatan dan proses belajar mengajar pada setiap mata pelajaran, cakupan dari masing - masing materi pelajaran tersebut diwujudkan melalui pada saat pelajaran yang berlangsung secara relevan.

\section{Materi Pokok yang dapat diimplementasikan pada pendidikan multikultural}

\begin{tabular}{|l|l|l|}
\hline \multicolumn{1}{|c|}{ Mata Pelajaran } & $\begin{array}{c}\text { Materi Pokok yang } \\
\text { dapat di } \\
\text { implementasikan } \\
\text { pendidikan } \\
\text { multikultural }\end{array}$ & \multicolumn{1}{|c|}{ Sub Materi } \\
\hline $\begin{array}{l}\text { Pendidikan Agama } \\
\text { dan Budi Pekerti }\end{array}$ & $\begin{array}{l}\text { Perilaku Terpuji } \\
\text { Menjadi Anak yang } \\
\text { baik }\end{array}$ & $\begin{array}{l}\text { Kerja Sama dan } \\
\text { tolong menolong } \\
\text { Hormat dan patuh } \\
\text { kepada orang tua dan } \\
\text { guru }\end{array}$ \\
\hline
\end{tabular}

${ }^{12}$ Bapak Chanafi, S.Pd, Interview, ruang Kepala Sekolah, tanggal 08 Juni 2019. ...:.:. Multicultural of 7dlamic Education Vol. 3 No.1 Oktaber 2019 :...... 


\begin{tabular}{|c|c|c|}
\hline & & $\begin{array}{l}\text { - Santun dan } \\
\text { menghargai kepada } \\
\text { teman } \\
\text { - } \begin{array}{l}\text { Indahnya saling } \\
\text { menghargai }\end{array}\end{array}$ \\
\hline $\begin{array}{l}\text { Pendidikan } \\
\text { Kewarganegaraan }\end{array}$ & $\begin{array}{l}\text { - } \text { Organisasi } \\
\text { - } \quad \text { Menghargai } \\
\text { keputusan bersama }\end{array}$ & 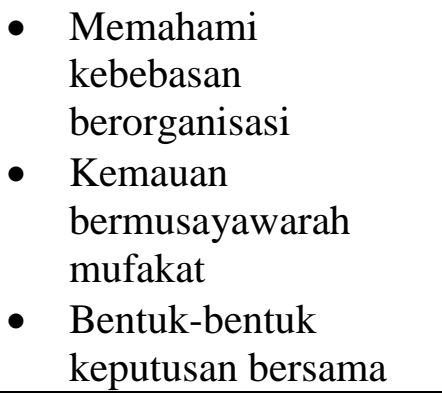 \\
\hline
\end{tabular}

\section{Implementasi pendidikan multikultural pada proses pembelajaran}

Implementasi pendidikan multikultural pada proses pembelajaran yang dilaksanakan di Sekolah Dasar Negeri Durensewu I Pandaan menggunakan pendekatan kontribusi dan aksi sosial, hal ini dikarenakan Sekolah Dasar Negeri Durensewu I Pandaan merupakan pendidikan formal yang berada dibawah lingkungan wilayah kerja UPT Pendidikan Kecamatan Pandaan.

Salah satu contoh saat mengunakan pendekatan kontribusi dan aksi sosial adalah saat siswa baru masuk sekolah dan sebelum melaksanakan kegiatan belajar mengajar toleransi dalam berdoa yang dilaksanakan disemua kelas yaitu kelas I sampai kelas VI Sekolah Dasar Negeri Durensewu I Pandaan. Implementasi toleransi ini dapat dilihat sebelum dan sesudah pelajaran. Disetiap kelas sebelum dan sesudah pelajaran di mulai dengan berdoa, dipimpin oleh salah satu siswa untuk maju kedepan kelas. Untuk peserta didik yang beragama non Muslim dipersilahkan berdoa sendiri sesuai dengan agama masing-masing. ${ }^{13}$

\section{Implementasi Pendidikan Multikultural pada kegiatan sekolah}

\footnotetext{
${ }^{13}$ Bapak Abdul Chalim, S.Pd, Interview, Ruang kelas V, tanggal 12 Juni 2019.
} 
Implementasi pendidikan multikultural pada kegiatan sekolah yang bisa diterapkan di Sekolah Dasar Negeri Durensewu I Pandaan menggunakan beberapa pendekatan yaitu:
a. Pendekatan Aditif
b. Pendekatan Kontribusi
c. Pendekatan aksi sosial
d. Pendekatan Pembiasaan

Contoh kegiatan Implementasi pendidikan multikultural menggunakan pendekatan diatas adalah adalah sebagai berikut:

Kegiatan berdoa sebelum dan sesudah kegiatan belajar mengajar dalam kegiatan ini semua siswa berdoa Kegiatan ini juga dilaksanakan oleh semua kelas di Sekolah Dasar Negeri Durensewu I Pandaan. Pada saat berdoa dipimpin oleh salah satu peserta didik dengan maju ke depan kelas untuk memimpin berdoa secara bersama-sama. Bagi kelas yang ada peserta didik non muslim tetap tinggal di dalam kelas dan dipersilahkan untuk berdoa sendiri berdasarkan agama dan keyakinannya.

Kegiatan menggunakan pendekatan sosial lainnya yang dilakukan di Sekolah Dasar Negeri Durensewu I Pandaan yaitu pada saat ada orang tua dari salah satu peserta didik yang meninggal peserta didik diintruksikan membawa beras sebanyak satu genggam tangan orang dewasa yang dikumpulkan disekolah melalui guru di masing-masing kelas, selanjutnya semua dewan guru membawa semua beras yang terkumpul dari siswa melayat kepada orangtua peserta didik yang meninggal tadi. Seperti firman Allah dalam al-Qur'an surat Al-Maidah ayat 2:

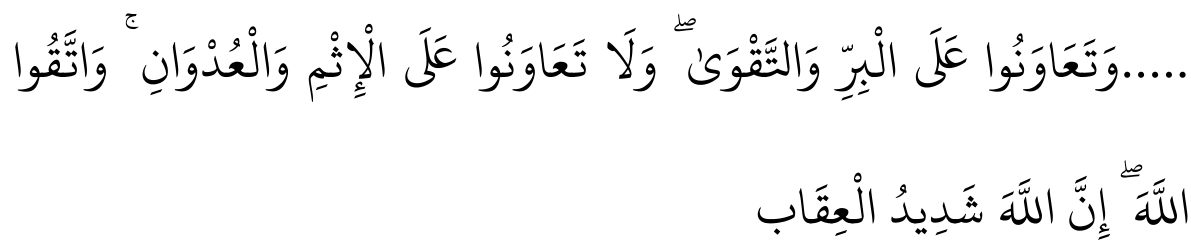

Artinya: 
"Dan tolong-menolonglah kamu dalam (mengerjakan) kebajikan dan takwa, dan jangan tolong-menolong dalam berbuat dosa dan pelanggaran. Dan bertakwalah kamu kepada Allah, sesungguhnya Allah amat berat siksa-Nya." ${ }^{, 14}$ (QS. Al Maidah [5]: 2).

zakat fitrah, semua siswa baik yang Islam diwajibkan untuk membawa beras dalam jumlah 3 (tiga) kilogram untuk zakat fitrah, sedangkan untuk siswa yang beragama non muslim dibebaskan mau membawa beras ataupun tidak membawa beras akan tetapi kejadian disekolah semua siswa non muslim tetap membawa beras untuk zakat fitrah meskipun tidak diwajibkan.

\section{Faktor yang mendukung dalam keberhasilan Konsep dan Implementasi Pendidikan Multikultural di Sekolah Dasar Negeri Durensewu I}

Keberhasilan dalam pelaksanaan pendidikan Multikultural di sekolah dipengaruhi oleh beberapa faktor dalam pelaksanaannya di Sekolah Dasar Negeri Durensewu I konsep dan implementasi pendidikan multikultural disesuaikan dengan beberapa konflik dan keluhan dari wali murid tentang adanya perbedaan agama dan kepercayaan serta budaya.

Faktor yang mempengaruhi keberhasilan dalam implementasi pendidikan multikultural di Sekolah Dasar Negeri Durensewu I diantaranya sebagai berikut:

Peran kepala sekolah dalam implementasi pendidikan multikultural

Peran kepala sekolah dalam implmentasi pendidikan multikultural di Sekolah Dasar Negeri Durensewu I sangat penting dalam menunjang keberhasilan implementasi pendidikan multikultural, hal ini dikarenkan kepala sekolah merupakan penghubung antara wali murid, warga masyarakat

\footnotetext{
${ }^{14}$ Departemen Agama Republik Indonesia, al-Qur'an dan Terjemah, QS. Al Hujurat [5]: 2, 106.
} 
sekitar serta kepada siswa siswi. Kepala sekolah juga merupakan perencana dan pembuat program untuk menunjang kegiatan pendidikan multicultural.

Peran guru dalam menerapkan pendidikan multikultural

Peran guru di Sekolah Dasar Negeri Durensewu I dalam keberhasilan pelaksanaan pendidikan multikultural sangat penting dikarenakan seorang guru itu menjadi gambaran siswa baik dari perkataan dan sikap, salah satu contohnya pada waktu pemilihan pengurus kelas guru memberikan contoh dalam memilih pengurus kelas semuanya siswa memiliki hak yang sama untuk dipilih serta memilih pengurus kelas.

Berdasarkan hasil penelitian sekaligus wawancara yang dilakukan di Sekolah Dasar Negeri Durensewu I Pandaan dapat ditarik kesimpulan sebagai berikut:

1. Konsep Pendidikan Multikultural di Sekolah Dasar Negeri Durensewu I Pandaan untuk mengembangkan sikap toleransi, saling menghargai, saling menghormati sesama manusia meskipun berbeda agama. memahami perbedaan serta persamaan peserta didik terkait dengan jenis kelamin, ras, budaya, etnik dan agama.

2. Implementasi Pendidikan Multikultural di Sekolah Dasar Negeri Durensewu I Pandaan dalam pelaksanaannya dilakukan dengan mencakupi dua komponen implementasi yaitu implementasi pada materi pelajaran, dan implementasi pada proses pelajaran.

3. Implementasi Pendidikan Multikultural berhasil karena ada factor yang mendukung diantaranya dari pihak sekolah, guru dan masyarakat sekitar.

\section{KESIMPULAN}

Berdasarkan hasil penelitian sekaligus wawancara yang dilakukan di Sekolah Dasar Negeri Durensewu I Pandaan dapat ditarik kesimpulan sebagai berikut: (1) Konsep Pendidikan Multikultural di Sekolah Dasar ...::: Multicultural of 7damic Education Vol. 3 No.1 Oktaber $2019:: . .$. . 
$26:$ :. Konsep dan Implementasi Pendidikan Multikultural di Sekolah Dasar (SD)

Negeri Durensewu 1

Negeri Durensewu I Pandaan untuk mengembangkan sikap toleransi, saling menghargai, saling menghormati sesama manusia meskipun berbeda agama. memahami perbedaan serta persamaan peserta didik terkait dengan jenis kelamin, ras, budaya, etnik dan agama. (2) Implementasi Pendidikan Multikultural di Sekolah Dasar Negeri Durensewu I Pandaan dalam pelaksanaannya dilakukan dengan mencakupi dua komponen implementasi yaitu implementasi pada materi pelajaran, dan implementasi pada proses pelajaran. (3) Implementasi Pendidikan Multikultural berhasil karena ada faktor yang mendukung diantaranya dari pihak sekolah, guru dan masyarakat sekitar

\section{DAFTAR PUSTAKA}

Suharjo, Mengenal Pendidikan Sekolah Dasar Teori dan Praktek, (Jakarta: Departemen Pendidikan Nasional Direktorat Jendral Pendidikan Tinggi Direktorat Ketenagaan, 2006), 1.

Tahir, Arifin. Kebijakan Publik \& Transparansi Penyelenggaraan Pemerintah Daerah.Cetakan Kesatu, (Bandung: Alfabeta CV, 2014), 55.

Maslikhah, Kebijakan Publik dan ..., 48.

Agus Iswanto, "Integrasi PAI dan PKn: mengupayakan Pai Yang Berwawasan Multikultural", dalam Pendidikan Agama Islam Dalam Perspektif Multikulturalisme, hlm. 10.

Data Dokumentasi Sekolah Dasar Negeri Durensewu I, SK Gubernur, dikutip tanggal 02 Juli 2019.

Departemen Agama Republik Indonesia, al-Qur'an dan Terjemah, QS. Al Hujurat [5]: 2, 106. 